\title{
Alkaloids Isolated from Natural Herbs as the Anticancer Agents
}

\author{
Jin-Jian Lu, Jiao-Lin Bao, Xiu-Ping Chen, Min Huang, and Yi-Tao Wang \\ State Key Laboratory of Quality Research in Chinese Medicine (University of Macau) and Institute of Chinese Medical Sciences, \\ University of Macau, Avenue Padre Toma’s Pereira, Taipa 999078, Macao, China
}

Correspondence should be addressed to Jin-Jian Lu, jinjianlu@umac.mo and Yi-Tao Wang, ytwang@umac.mo

Received 11 May 2012; Revised 17 July 2012; Accepted 30 July 2012

Academic Editor: Alvin J. Beitz

Copyright ( 92012 Jin-Jian Lu et al. This is an open access article distributed under the Creative Commons Attribution License, which permits unrestricted use, distribution, and reproduction in any medium, provided the original work is properly cited.

\begin{abstract}
Alkaloids are important chemical compounds that serve as a rich reservoir for drug discovery. Several alkaloids isolated from natural herbs exhibit antiproliferation and antimetastasis effects on various types of cancers both in vitro and in vivo. Alkaloids, such as camptothecin and vinblastine, have already been successfully developed into anticancer drugs. This paper focuses on the naturally derived alkaloids with prospective anticancer properties, such as berberine, evodiamine, matrine, piperine, sanguinarine, and tetrandrine, and summarizes the mechanisms of action of these compounds. Based on the information in the literature that is summarized in this paper, the use of alkaloids as anticancer agents is very promising, but more research and clinical trials are necessary before final recommendations on specific alkaloids can be made.
\end{abstract}

\section{Introduction}

Alkaloids are a highly diverse group of compounds that contain a ring structure and a nitrogen atom. In most cases, the nitrogen atom is located inside the heterocyclic ring structure [1]. A classification based on biosynthetic pathways is mostly used to categorize different alkaloid [1]. Alkaloids have a wide distribution in the plant kingdom and mainly exist in higher plants, such as those belonging to Ranunculaceae, Leguminosae, Papaveraceae, Menispermaceae, and Loganiaceae [1]. Moreover, several alkaloids exhibit significant biological activities, such as the relieving action of ephedrine for asthma, the analgesic action of morphine, and the anticancer effects of vinblastine [1-4]. In fact, alkaloids are among the most important active components in natural herbs, and some of these compounds have already been successfully developed into chemotherapeutic drugs, such as camptothecin (CPT), a famous topoisomerase I (TopI) inhibitor [5], and vinblastine, which interacts with tubulin [4].

Herein, we searched the PubMed database and the naturally derived alkaloids, such as berberine, evodiamine, matrine, piperine, sanguinarine, and tetrandrine (Figure 1), which have relatively more anticancer studies, have been selected for reviewing. Other alkaloids (such as chelerythrine, chelidonine, fagaronine, lycorine, nitidine chloride, and solanine) lacking systematic anticancer investigations have also been mentioned. The aim of this paper is to summarize and investigate the mechanisms of action of these compounds to accelerate the discovery of anticancer drugs derived from alkaloids. We propose that the development of alkaloids into new anticancer agents has a bright future despite some difficulties.

\section{Alkaloids with Anticancer Effects and the Related Mechanisms}

2.1. Berberine. Berberine (Figure 1) is an isoquinoline alkaloid widely distributed in natural herbs, including Rhizoma Coptidis, a widely prescribed Chinese herb [6]. It has a broad range of bioactivities, such as antiinflammatory, antibacterial, antidiabetes, antiulcer, sedation, protection of myocardial ischemia-reperfusion injury, expansion of blood vessels, inhibition of platelet aggregation, hepatoprotective, and neuroprotective effects [7-11]. Berberine has been used in the treatment of diarrhea, neurasthenia, arrhythmia, diabetes, and so forth [11]. Several studies have shown that 
<smiles>COc1ccc2cc3[n+](cc2c1OC)CCc1cc2c(cc1-3)OCO2</smiles>

Berberine<smiles>O=C(/C=C/C=C/c1ccc2c(c1)OCO2)N1CCCCC1</smiles>

Piperine<smiles>CN1c2ccccc2C(=O)N2CCc3c([nH]c4ccccc34)C21</smiles>

Evodiamine<smiles>C[n+]1cc2c3c(ccc2c2ccc4cc5c(cc4c21)OCO5)OCO3</smiles>

Sanguinarine<smiles>O=C1CCCC2C3CCCN4CCCC(CN12)C34</smiles>

Matrine

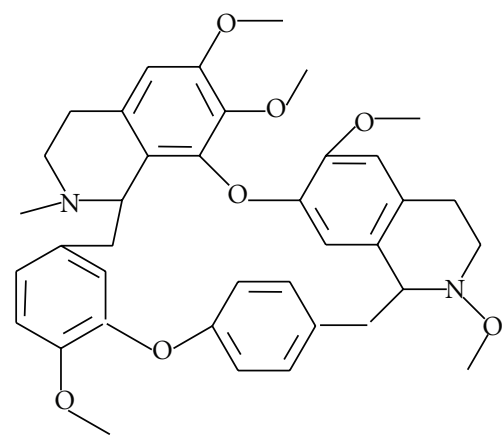

Tetrandrine

FIgURE 1: The chemical structures of berberine, evodiamine, matrine, piperine, sanguinarine, and tetrandrine.

berberine has anticancer potentials by interfering with the multiple aspects of tumorigenesis and tumor progression in both in vitro and in vivo experiments. These observations have been well summarized in the recent reports [12-14]. Berberine inhibits the proliferation of multiple cancer cell lines by inducing cell cycle arrest at the $\mathrm{G}_{1}$ or $\mathrm{G}_{2} / \mathrm{M}$ phases and by apoptosis $[12,15,16]$. In addition, berberine induces endoplasmic reticulum stress [15] and autophagy [17] in cancer cells. However, compared with clinically prescribed anticancer drugs, the cytotoxic potency of berberine is much lower, with an $\mathrm{IC}_{50}$ generally at $10 \mu \mathrm{M}$ to $100 \mu \mathrm{M}$ depending on the cell type and treatment duration in vitro [12]. Besides, berberine also induces morphologic differentiation in human teratocarcinoma cells [18]. Inhibition of tumor invasion and metastasis is an important aspect of berberine's anticancer activities $[19,20]$. A few studies have reported berberine's inhibition of tumor angiogenesis [21, 22]. In addition, its combination with chemotherapeutic drugs or irradiation could enhance the therapeutic effects [23, $24]$. Recently, a study reported that berberine also showed promising chemopreventive efficacy in hamster buccal pouch carcinogenesis [25].

The potential molecular targets and mechanisms of berberine are rather complicated. Berberine interacts with DNA or RNA to form a berberine-DNA or a berberine-RNA complex, respectively $[26,27]$. Berberine is also identified as an inhibitor of several enzymes, such as $\mathrm{N}$-acetyltransferase (NAT), cyclooxygenase-2 (COX-2), and telomerase [12]. Other mechanisms of berberine are mainly related to its effect on cell cycle arrest and apoptosis, including regulation of cyclin-dependent kinase (CDK) family of proteins [12, 28] and expression regulation of B-cell lymphoma 2 (Bcl2) family of proteins (such as Bax, Bcl-2, and Bcl-xL)
$[12,15,28]$, and caspases $[15,28]$. Furthermore, berberine inhibits the activation of the nuclear factor $\kappa$-light-chainenhancer of activated $\mathrm{B}$ cells $(\mathrm{NF}-\kappa \mathrm{B})$ and induces the formation of intracellular reactive oxygen species (ROS) in cancer cells $[12,15]$. Interestingly, these effects might be specific for cancer cells [12]. The effect of berberine on invasion, migration, metastasis, and angiogenesis is mediated through the inhibition of focal adhesion kinase (FAK), NF$\kappa \mathrm{B}$, urokinase-type plasminogen-activator (u-PA), matrix metalloproteinase 2 (MMP-2), and matrix metalloproteinase 9 (MMP-9) [20, 29]; reduction of Rho kinase-mediated Ezrin phosphorylation [19]; reduction of the expression of COX-2, prostaglandin E, and prostaglandin E receptors [30]; downregulation of hypoxia-inducible factor 1 (HIF-1), vascular endothelial growth factor (VEGF), proinflammatory mediators [21,22], and so forth.

2.2. Evodiamine. Evodiamine (Figure 1), a quinolone alkaloid, is one of the major bioactive compounds isolated from the Chinese herb Evodia rutaecarpa. It possesses antianxiety, antiobese, antinociceptive, antiinflammatory, antiallergic, and anticancer effects. Besides, it has thermoregulation, protection of myocardial ischemia-reperfusion injury and vessel-relaxing activities [11,31-34]. Evodiamine exhibits anticancer activities both in vitro and in vivo by inducing the cell cycle arrest or apoptosis, inhibiting the angiogenesis, invasion, and metastasis in a variety of cancer cell lines [35-39]. It presents anticancer potentials at micromolar concentrations and even at the nanomolar level in some cell lines in vitro [40,41]. Evodiamine also stimulates autophagy, which serves as a survival function [42]. Compared with other compounds, evodiamine is less toxic to normal human cells, such as human peripheral blood mononuclear cells 
$[37,43]$. It also inhibits the proliferation of adriamycinresistant human breast cancer NCI/ADR-RES cells both in vitro and in Balb-c/nude mice [44]. Evodiamine $(10 \mathrm{mg} / \mathrm{kg})$ administrated orally twice daily significantly inhibits the tumor growth [44]. Moreover, treatment with $10 \mathrm{mg} / \mathrm{kg}$ evodiamine from the 6th day after tumor inoculation into mice reduces lung metastasis and does not affect the body weight of mice during the experimental period [35].

Evodiamine inhibits TopI enzyme, forms the DNA covalent complex with a similar concentration to that of CPT, and induces DNA damage [45-47]. However, TopI may not be the main target of this compound. Cancer cells treated with evodiamine exhibit $\mathrm{G}_{2} / \mathrm{M}$ phase arrest $[44,48,49]$ rather than $S$ phase arrest, which is not consistent with the mechanism of classic TopI inhibitors, such as CPT. Therefore, other targets aside from TopI may also be important for realizing the anticancer potentials of evodiamine. This statement is supported by the fact that evodiamine has effect on tubulin polymerization [49]. Exposure to evodiamine rapidly increases intracellular ROS followed by an onset of mitochondrial depolarization [50]. The generation of ROS and nitric oxide acts in synergy and triggers mitochondriadependent apoptosis [42]. Evodiamine also induces caspasedependent and caspase-independent apoptosis, downregulates Bcl-2 expression, and upregulates Bax expression in some cancer cells $[38,40]$. The phosphatidylinositol 3kinase/Akt/caspase and Fas ligand (Fas-L)/NF- $\kappa \mathrm{B}$ signaling pathways might account for evodiamine-induced cell death. Moreover, these signals could be increased by the ubiquitinproteasome pathway [41].

2.3. Matrine. Matrine (Figure 1) is a major alkaloid found in many Sophora plants, including Sophora flavescens Ait. [51]. It exhibits a wide range of pharmacological properties such as antibacterial, antiviral, antiinflammatory, antiasthmatic, antiarrhythmic, antiobesity, anticancer, diuretic, choleretic, hepatoprotective, nephroprotective, and cardioprotective effects [11, 52-58]. It has been used for treatment of bacillary dysentery, enteritis, malignant pleural effusion, and so forth in China [11], and the anticancer effects have also been widely studied [59-61]. Although the needed concentration of matrine to inhibit cancer cell proliferation is relatively high (i.e., at millimolar level) $[59,60]$, it has no significant effects on the viability of normal cells [60]. Matrine inhibits the proliferation of various types of cancer cells mainly through mediation of $\mathrm{G}_{1}$ cell cycle arrest or apoptosis [59, 60, 62-64]. Apoptosis and autophagy could be both induced by matrine in human cancer cells, such as hepatoma G2 cells and SGC7901 cells $[65,66]$. Matrine also induces the differentiation of K562 cells and presents antiangiogenesis activities $[67,68]$. The in vivo anticancer efficacy of matrine has already been evaluated in $\mathrm{H} 22$ cells, MNNG/HOS cells, 4T1 cells and $\mathrm{BxPC}-3$ cells in BALB/c mice, among others $[60,61,68,69]$. For example, matrine at $50 \mathrm{mg} / \mathrm{kg}$ or $100 \mathrm{mg} / \mathrm{kg}$ inhibits MNNG/HOS xenograft growth [61], and it reduces the pancreatic tumor volumes compared to those of control at the similar doses [60].

However, the exact targets of matrine are still unclear. Matrine affects many proteins involved in cell proliferation or apoptosis, such as E2F-1, Bax, Bcl-2, Fas, and Fas-L [59-61, 63, 64, 70]. It inhibits cancer cell invasion partially through inhibition of MMP-2 and MMP-9 expression and modulation of the NF- $\kappa \mathrm{B}$ signaling pathway [71-73]. Matrine has been used in China for cancer therapy. The direct inhibition of cancer proliferation by this compound seems not to be the exact mechanism that could explain the reason for its application in cancer treatment.

2.4. Piperine. Piperine (Figure 1), a piperidine alkaloid isolated from Piper nigrum and Piper longum, is a compound found in famous spices that have been used for centuries [74]. It exhibits antioxidant, antiinflammatory, antidiarrheal, anticonvulsant, antimutagenic, hypolipidemic, promoting bile secretion, and tumor inhibitory activities $[11,75,76]$. It is also a known antidepressant of the central nervous system $[77,78]$. The chemopreventive effects of piperine against several kinds of carcinogen, such as benzo(a)pyrene, and 7,12-dimethyl benz(a)anthracene, show its potential as a cancer preventive agent [79-85]. Administration of piperine $(50 \mathrm{mg} / \mathrm{kg}$ or $100 \mathrm{mg} / \mathrm{kg}$ per day for 7 days) inhibits solid tumor development in mice transplanted with sarcoma 180 cells [86]. A recent study has shown that piperine inhibits breast stem cell self-renewal and does not cause toxicity to differentiated cells [87]. It has been demonstrated that piperine induced apoptosis and increased the percentage of cells in $\mathrm{G}_{2} / \mathrm{M}$ phase in $4 \mathrm{~T} 1$ cells and induced $\mathrm{K} 562$ cells to differentiate into macrophages/monocytes $[88,89]$. Piperine also has very good antimetastatic properties against lung metastasis induced by B16F-10 melanoma cells in mice $(200 \mu \mathrm{M} / \mathrm{kg})[90]$ and suppresses phorbol-12-myristate-13acetate (PMA)-induced tumor cell invasion [91].

Piperine is a potent inhibitor of NF- $\kappa$ B, c-Fos, cAMP response element-binding (CREB), activated transcription factor 2 (ATF-2), among others. [92]. It suppresses PMA-induced MMP-9 expression via the inhibition of PKC $\alpha$ /extracellular signal-regulated kinase (ERK) $1 / 2$ and reduction of NF- $\kappa$ B/AP-1 activation [91]. Remarkably, piperine also inhibits the functions of P-glycoprotein (P-gp) and CYP3A4, which not only affects drug metabolism but also re-sensitizes multidrug resistant (MDR) cancer cells $[93,94]$. Piperine increases the therapeutic efficacy of docetaxel in a xenograft model without inducing more adverse effects on the treated mice by inhibiting CYP3A4, one of the main metabolizing enzymes of docetaxel [95].

2.5. Sanguinarine. Sanguinarine (Figure 1) is a benzophenanthridine alkaloid isolated from the Papaveracea family, which includes Sanguinaria canadensis L. and Chelidonium majus L. [96, 97]. It has antibacterial, antifungal, antischistosomal, antiplatelet, and antiinflammatory properties $[11,98-100]$, and is used for schistosomiasis control [11]. Sanguinarine also exhibits anticancer potentials [101-104] and is currently receiving attention from researchers. Data from in vitro studies indicates that this alkaloid presents anticancer effects at concentrations less than ten micromoles in most cases. Sanguinarine induces cell cycle arrest at different phases or apoptosis in a variety of cancer cells 
[101, 102, 104-107]. It remarkably sensitizes breast cancer cells to tumor necrosis factor (TNF)-related apoptosisinducing ligand-mediated apoptosis [105]. Sanguinarine also shows antiangiogenic effects in mice $(5 \mathrm{mg} / \mathrm{kg})$, presents anti-invasive effects, and overcomes P-gp-mediated MDR phenotype [108-110]. A strategy involving the coadministration of COX-2 inhibitors and sanguinarine has been recommended for the management of prostate cancer [111]. It has also been suggested that sanguinarine may be developed as an agent for the management of conditions elicited by ultraviolet exposure such as skin cancer [112].

The most possible mechanism responsible for the anticancer effects of this compound is its ability to directly interact with glutathione (GSH). This interaction severely depletes cellular GSH and induces ROS generation [102, 103, $105,113]$. Pretreatment of $\mathrm{N}$-acetyl cysteine or catalase prevents the sanguinarine-induced ROS production and cytotoxicity $[102,113]$. This mechanism is very similar to that of the TopII inhibitor salvicine, a diterpene quinone synthesized via the structural modification of a natural compound isolated from Salvia prionitis lance $[114,115]$. Sanguinarine is a selective inhibitor of mitogen-activated protein kinase phosphatase 1 (MKP-1), which is overexpressed in many tumor cells [116]. The disruption of microtubule assembly dynamics [117], the nucleocytoplasmic trafficking of cyclin D1 and TopII [118], and the induction of DNA damage [109] also contributes to, at least in part, the anticancer effects of this compound. Sanguinarine is a potent suppressor of NF- $\kappa \mathrm{B}$ activation induced by TNF, interleukin-1, phorbol ester, and okadaic acid, but not that activated by hydrogen peroxide or ceramide [119]. It also effectively inhibits the signal transducer and activator of transcription 3 activation (STAT-3) [120]; downregulates CDKs, cyclins, MMP-2, and MMP-9 [107, 110]; upregulates p21, p27 [107], and the phosphorylation of p53 [101]; modulates the members of the Bcl-2 family including Bax, Bak, Bid, Bcl-2, and Bcl-xL [101, 105, 106]; activates caspases [104-106]; and upregulates death receptor 5 (DR-5) [104].

2.6. Tetrandrine. Tetrandrine (Figure 1), a bisbenzylisoquinoline alkaloid from the root of Stephania tetrandra, exhibits a broad range of pharmacological activities, including immunomodulating, antihepatofibrogenetic, antiinflammatory, antiarrhythmic, antiportal hypertension, anticancer and neuroprotective activities $[11,121]$. It generally presents its anticancer effects in the micromolar concentrations. Tetrandrine induces different phases of cell cycle arrest, depends on cancer cell types [122-124], and also induces apoptosis in many human cancer cells, including leukemia, bladder, colon, hepatoma, and lung [122-130]. In vivo experiments have also demonstrated the potential value of tetrandrine against cancer activity $[126,127,131]$. For example, the survival of mice subcutaneously inoculated with CT-26 cells is extended after daily oral gavage of $50 \mathrm{mg} / \mathrm{kg}$ or $150 \mathrm{mg} / \mathrm{kg}$ of tetrandrine [127]. Tetrandrine also inhibits the expression of VEGF in glioma cells, has cytotoxic effect on ECV304 human umbilical vein endothelial cells, and suppresses in vivo angiogenesis [131]. Tetrandrine-treated mice $(10 \mathrm{mg} / \mathrm{kg} /$ day) have fewer metastases than vehicletreated mice, and no acute toxicity or obvious changes can be observed in the body weight of both groups [132].

Coadministration of tetrandrine restores the sensitivity of MDR cancer cells to doxorubicin, paclitaxel, docetaxel, and vincristine [133-135] through the inhibition of P-gp. In mice with MDR MCF-7/adr or KBv200 cell xenografts, co-administration of tetrandrine increases the anticancer activity of doxorubicin and vincristine without a significant increase in toxicity $[133,135]$. Hence, tetrandrine holds a great promise as a MDR modulator for the treatment of P-gp-mediated MDR cancers. Tetrandrine appears to be a promising candidate for combining with several chemotherapeutic agents, such as 5-fluorouracil and cisplatin, in vitro or in vivo [126, 136, 137]. It enhances tamoxifeninduced antiproliferation by inhibiting phosphoinositidedependent kinase 1 [138]. Tetrandrine also enhances the radio sensitivity of various cancer cells mainly by affecting the radiation-induced cell cycle arrest and redistributing the cell cycle [139-143]. All these observations are rational evidence supporting the application of tetrandrine as an adjunct for cancer chemotherapy or radiotherapy.

Activation of glycogen synthase kinase $3 \beta$ (GSK-3 $\beta$ ), generation of ROS, activation of p38 mitogen-activated protein kinase (p38 MAPK), and inhibition of Wnt/betacatenin signaling might contribute to the anticancer effects of tetrandrine $[126,127,144-146]$. Tetrandrine also effectively up-regulates p53, p21, p27, and Fas [123, 124, 145, 147]; down-regulates Akt phosphorylation, CDKs, and cyclins $[124,145,148]$; modulates the members of the Bcl-2 family including Bax, Bcl-xL, and Bid [147, 148]; activates caspases $[145,147]$.

2.7. Other Alkaloids with Anticancer Effects. Aside from the aforementioned alkaloids, other alkaloids such as chelerythrine isolated from Toddalia asiatica (L.) Lam, chelidonine isolated from Chelidonium majus L., fagaronine isolated from Fagara zanthoxyloides Lam., lycorine isolated from Lycoris, nitidine chloride isolated from Zanthoxylum nitidum (Roxb.) DC., solanine isolated from Solanum tuberosum, sophocarpine isolated from Sophora alopecuroides L., trigonelline isolated from trigonella foenum-graecum also present anticancer potentials with diversiform mechanisms [11, 149153]. However, reports on the anticancer activities and underlying mechanism of actions of these compounds are limited.

\section{Discussion}

In this paper, we summarized the recent progress of several typical alkaloids with anticancer activities and presented some characteristics of these compounds. On the basis of the previous studies, alkaloids with anticancer activities reflect diversity at least in three aspects.

First, the source of alkaloids with anticancer potentials is very extensive. Most of the aforementioned alkaloids are from different families, and the biosynthesis of these compounds is also varied. For example, berberine is isolated from 

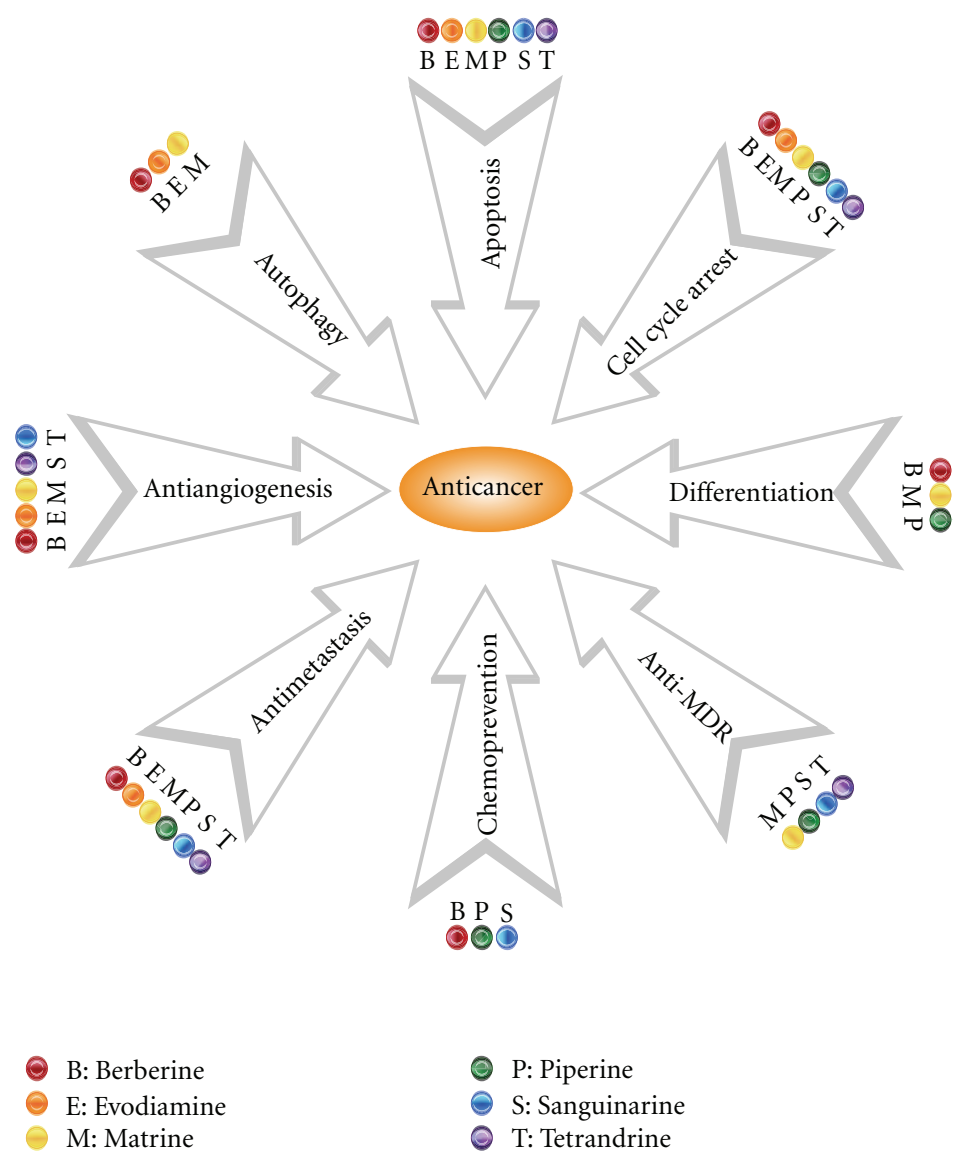

FIGURE 2: Berberine, evodiamine, matrine, piperine, sanguinarine, and tetrandrine restrain cancer by modulating multiple signaling pathways, resulting in the inhibition of the initiation of carcinogenesis, induction of cell cycle arrest, apoptosis, autophagy, or differentiation, and inhibition of metastasis, angiogenesis, and so forth.

Ranunculaceae and roots in phenylalanine and tyrosine, whereas evodiamine is isolated from Rutaceae and roots in tryptophan [1]. Second, the pharmacological activities of these alkaloids are varied $[11,12,154]$. For instance, piperine and berberine are used to treat epilepsy and diarrhea, respectively $[155,156]$, and both of these compounds show anticancer and other pharmacological effects. Third, the research focuses of these anticancer alkaloids are also very different. Research on piperine is usually focused on cancer prevention $[82,85]$, whereas that on most other alkaloids is mainly focused on cancer chemotherapy, especially on the evaluation of antiproliferative activity [12, 37, 113, 124]. Figure 2 summarizes the different roles of the aforementioned six alkaloids to achieve their anticancer effects.

In addition to their diversity, the anticancer alkaloids also have several other characteristics or/and issues which should be addressed. First, the range of alkaloid concentration necessary to elicit the anticancer effects is wide $[4,5,12$, $60,124]$. The needed concentration is relatively higher for most of the aforementioned alkaloids to produce anticancer effects, compared with the widely used chemotherapeutic drugs such as CPT [5] and vinblastine [4], although both are also naturally derived alkaloids. The concentration of matrine used to produce anticancer effects even reaches millimole [60]. Therefore, modification of the compound via chemical methods may be a good strategy. This observation also indicates that combination therapy probably provides an optimal venue for the clinical application of these compounds because most of these alkaloids exhibit synergistic or enhancement effects when combined with chemotherapeutic drugs in both in vitro and in vivo experiments $[95,136,157$, 158].

Second, alkaloids isolated from natural herbs seem to have many targets to realize their multiple pharmacological effects (Figure 3), indicating that most of them are "dirty compounds." These "dirty compounds" are a pressing medical necessity, especially for the treatment of complex diseases such as cancer [159]. However, the discovery of the molecular targets and mechanisms of these alkaloids still has a long way to go. Recent developments in biology, such as the emergence of the "-omics" fields of study, surface plasmon resonance technology, and siRNA, may greatly facilitate researches in this area $[4,160-163]$.

Third, most of these alkaloids have poor water solubility and low bioavailability and are hard to reach the specific cancer site. In addition to the structural modification, changing the drug delivery system could be another strategy. The development of nanotechnology may bring hope to solve 


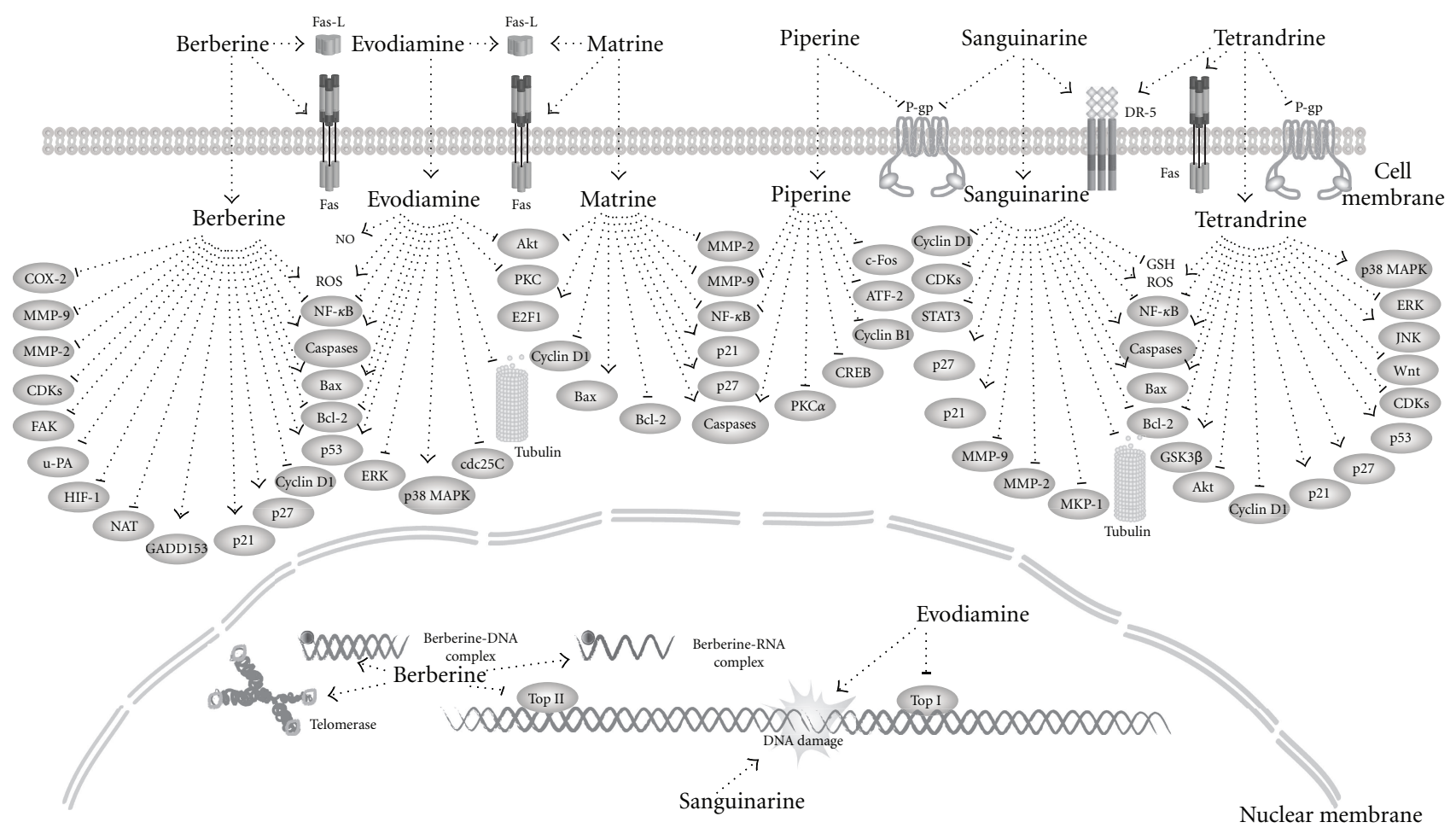

$\cdots>$ : Activation or upregulation

$\cdots$... Inhibition or downregulation

FIGURE 3: The schematic diagram of the molecular machinery and possible targets for the antineoplastic properties of berberine, evodiamine, matrine, piperine, sanguinarine, and tetrandrine. ATF-2: activated transcription factor 2; Bax: Bcl-2-associated X protein; Bcl-2: B-cell lymphoma 2; CDKs: cyclin-dependent kinases; COX-2: cyclooxygenase 2; CREB: cAMP response element-binding; DR-5: death receptor 5; ERK: extracellular signal-regulated kinase; FAK: focal adhesion kinase; Fas-L: Fas ligand; GADD153: growth arrest and DNA-damageinducible gene 153; GSH: glutathione; GSK3 $\beta$ : glycogen synthase kinase 3 $\beta$; HIF-1: hypoxia-inducible factor 1; MKP-1: mitogen-activated protein kinase phosphatase 1; MMP-2: matrix metalloproteinase 2; MMP-9: matrix metalloproteinase 9; NAT: N-acetyltransferase; NF- $\kappa \mathrm{B}$ : nuclear factor $\kappa$-light-chain-enhancer of activated B cells; NOS: nitric oxide synthase; p38 MAPK: p38 mitogen-activated protein kinase; PKC: protein kinase C; P-gp: P-glycoprotein; ROS: reactive oxygen species; STAT-3: signal transducer and activator of transcription 3; TopI: topoisomerase I; TopII: topoisomerase II; u-PA: urokinase-type plasminogen-activator.

these problems, and actually, there have been already some successful cases $[164,165]$.

Fourth, the toxicity of these compounds also cannot be ignored. For example, the most common side effects of berberine include anaphylaxis, constipation, and skin allergies [166]. Berberine can displace bilirubin from serumbinding proteins and cause kernicterus, jaundice, and brain damage in infants [166-168]. Neurotoxicity, immunotoxicity, and reproductive toxicity induced by piperine have been reported [169-171], and hepatotoxicity and embryonic toxicity can also be induced by sanguinarine [172, 173]. Therefore, alkaloids isolated from natural herbs are not always safe. The dosages, the routes of administration and the treatment procedures, among others, are very important. The transformation of chemical structures and the application of new drug delivery systems may reduce the toxicities of these compounds.

Finally, though there are several clinical studies of the alkaloids for the treatment of other diseases, for example, berberine for the treatment of diabetes or metabolic syndrome, there is no report about the clinical trial for cancer prevention or treatment using the aforementioned alkaloids. As there is a big jump from experiment researches to clinical ones, it is necessary to carry out some clinical anticancer trials for these alkaloids, such as berberine and tetrandrine.

In conclusion, for the future work in the field, (1) the exact anticancer mechanisms of alkaloids should be further identified using new pharmacological technologies; (2) the chemical structures of these lead compounds may be transformed via pharmaceutical chemistry; (3) the effective combinational therapy methods may be explored; (4) the effective drug delivery systems need to be developed; (5) the additional clinical anticancer trials for these alkaloids need to be performed.

\section{Conflict of Interests}

The authors declare that they have no conflict of interests. 


\section{Acknowledgments}

This study was supported by the Research Fund of University of Macau (UL016/09Y4/CMS/WYT01/ICMS and MYRG208(Y2-L4)-ICMS11-WYT) and the Macao Science and Technology Development Fund (077/2011/A3).

\section{References}

[1] Z. T. Wang and G. Y. Liang, Zhong Yao Hua Xue, Shanghai Scientific \& Technical, 2009.

[2] M. R. Lee, “The history of Ephedra (ma-huang)," Journal of the Royal College of Physicians of Edinburgh, vol. 41, no. 1, pp. 78-84, 2011.

[3] S. Benyhe, "Morphine: new aspects in the study of an ancient compound," Life Sciences, vol. 55, no. 13, pp. 969-979, 1994.

[4] W. Li, Y. Shao, L. Hu et al., "BM6, a new semi-synthetic Vinca alkaloid, exhibits its potent in vivo anti-tumor activities via its high binding affinity for tubulin and improved pharmacokinetic profiles," Cancer Biology and Therapy, vol. 6, no. 5, pp. 787-794, 2007.

[5] M. Huang, H. Gao, Y. Chen et al., "Chimmitecan, a novel 9-substituted camptothecin, with improved anticancer pharmacologic profiles in vitro and in vivo," Clinical Cancer Research, vol. 13, no. 4, pp. 1298-1307, 2007.

[6] J. Chen, H. ZHao, X. Wang, F. S. C. Lee, H. Yang, and L. Zheng, "Analysis of major alkaloids in Rhizoma coptidis by capillary electrophoresis-electrospray-time of flight mass spectrometry with different background electrolytes," Electrophoresis, vol. 29, no. 10, pp. 2135-2147, 2008.

[7] H. H. Yu, K. J. Kim, J. D. Cha et al., "Antimicrobial activity of berberine alone and in combination with ampicillin or oxacillin against methicillin-resistant Staphylococcus aureus," Journal of Medicinal Food, vol. 8, no. 4, pp. 454 461, 2005.

[8] C. W. Lau, X. Q. Yao, Z. Y. Chen, W. H. Ko, and Y. Huang, "Cardiovascular actions of berberine," Cardiovascular Drug Reviews, vol. 19, no. 3, pp. 234-244, 2001.

[9] J. Han, H. Lin, and W. Huang, "Modulating gut microbiota as an anti-diabetic mechanism of berberine," Medical Science Monitor, vol. 17, no. 7, pp. RA164-RA167, 2011.

[10] S. K. Kulkarni and A. Dhir, "Berberine: a plant alkaloid with therapeutic potential for central nervous system disorders," Phytotherapy Research, vol. 24, no. 3, pp. 317-324, 2010.

[11] Y. B. Ji, Active Ingredients of Traditional Chinese Medicine: Pharmacology and Application, People's Medical Publishing Hourse Cp., LTD, 2011.

[12] Y. Sun, K. Xun, Y. Wang, and X. Chen, "A systematic review of the anticancer properties of berberine, a natural product from Chinese herbs," Anti-Cancer Drugs, vol. 20, no. 9, pp. 757-769, 2009.

[13] C. V. Diogo, N. G. Machado, I. A. Barbosa, T. L. Serafim, A. Burgeiro, and P. J. Oliveira, "Berberine as a promising safe anti-cancer agent-is there a role for mitochondria?" Current Drug Targets, vol. 12, no. 6, pp. 850-859, 2011.

[14] W. Tan, J. Lu, M. Huang et al., "Anti-cancer natural products isolated from chinese medicinal herbs," Chinese Medicine, vol. 6, no. 1, p. 27, 2011.

[15] K. S. Eom, H. J. Kim, H. S. So, R. Park, and T. Y. Kim, "Berberine-induced apoptosis in human glioblastoma T98G Cells Is mediated by endoplasmic reticulum stress accompanying reactive oxygen species and mitochondrial dysfunction," Biological and Pharmaceutical Bulletin, vol. 33, no. 10, pp. 1644-1649, 2010.
[16] A. Burgeiro, C. Gajate, E. H. Dakir, J. A. Villa-Pulgarín, P. J. Oliveira, and F. Mollinedo, "Involvement of mitochondrial and B-RAF/ERK signaling pathways in berberine-induced apoptosis in human melanoma cells," Anti-Cancer Drugs, vol. 22, no. 6, pp. 507-518, 2011.

[17] N. Wang, Y. Feng, M. Zhu et al., "Berberine induces autophagic cell death and mitochondrial apoptosis in liver cancer cells: the cellular mechanism," Journal of Cellular Biochemistry, vol. 111, no. 6, pp. 1426-1436, 2010.

[18] K. S. S. Chang, C. Gao, and L. C. Wang, "Berberine-induced morphologic differentiation and down-regulation of c-Kiras2 protooncogene expression in human teratocarcinoma cells," Cancer Letters, vol. 55, no. 2, pp. 103-108, 1990.

[19] F. Tang, D. Wang, C. Duan et al., "Berberine inhibits metastasis of nasopharyngeal carcinoma $5-8 \mathrm{~F}$ cells by targeting rho kinase-mediated ezrin phosphorylation at threonine 567," Journal of Biological Chemistry, vol. 284, no. 40, pp. 2745627466, 2009.

[20] Y. T. Ho, J. S. Yang, T. C. Li et al., "Berberine suppresses in vitro migration and invasion of human SCC-4 tongue squamous cancer cells through the inhibitions of FAK, IKK, NF- $\kappa$ B, u-PA and MMP-2 and -9," Cancer Letters, vol. 279, no. 2, pp. 155-162, 2009.

[21] S. Jie, H. Li, Y. Tian et al., "Berberine inhibits angiogenic potential of Hep G2 cell line through VEGF down-regulation in vitro," Journal of Gastroenterology and Hepatology, vol. 26, no. 1, pp. 179-185, 2011.

[22] T. P. Hamsa and G. Kuttan, "Antiangiogenic activity of berberine is mediated through the downregulation of hypoxia-inducible factor-1, VEGF, and proinflammatory mediators," Drug and Chemical Toxicology, vol. 35, no. 1, pp. 57-70, 2012.

[23] M. J. Youn, H. S. So, H. J. Cho et al., "Berberine, a natural product, combined with cisplatin enhanced apoptosis through a mitochondria/caspase-mediated pathway in HeLa cells," Biological and Pharmaceutical Bulletin, vol. 31, no. 5, pp. 789-795, 2008.

[24] J. M. Hur, M. S. Hyun, S. Y. Lim, W. Y. Lee, and D. Kim, "The combination of berberine and irradiation enhances anti-cancer effects via activation of p38 MAPK pathway and ROS generation in human hepatoma cells," Journal of Cellular Biochemistry, vol. 107, no. 5, pp. 955-964, 2009.

[25] S. Manoharan, G. Sindhu, V. Vinothkumar et al., "Berberine prevents 7,12-dimethylbenz[a] anthracene-induced hamster buccal pouch carcinogenesis: a biochemical approach," European Journal of Cancer Prevention, vol. 21, no. 2, pp. 182-192, 2012.

[26] X. L. Li, Y. J. Hu, H. Wang et al., "Molecular spectroscopy evidence for berberine binding to DNA: comparative binding and thermodynamic profile of intercalation," Biomacromolecules, vol. 13, no. 3, pp. 873-880, 2012.

[27] M. M. Islam and G. Suresh Kumar, "RNA-binding potential of protoberberine alkaloids: spectroscopic and calorimetric studies on the binding of berberine, palmatine, and coralyne to protonated RNA structures," DNA and Cell Biology, vol. 28, no. 12, pp. 637-650, 2009.

[28] S. K. Mantena, S. D. Sharma, and S. K. Katiyar, "Berberine, a natural product, induces G1-phase cell cycle arrest and caspase-3-dependent apoptosis in human prostate carcinoma cells," Molecular Cancer Therapeutics, vol. 5, no. 2, pp. 296-308, 2006.

[29] T. P. Hamsa and G. Kuttan, "Berberine inhibits pulmonary metastasis through down-regulation of MMP in metastatic 
B16F-10 melanoma cells," Phytotherapy Research, vol. 26, no. 4, pp. 568-578, 2011.

[30] T. Singh, M. Vaid, N. Katiyar, S. Sharma, and S. K. Katiyar, "Berberine, an isoquinoline alkaloid, inhibits melanoma cancer cell migration by reducing the expressions of cyclooxygenase-2, prostaglandin $\mathrm{E}$ and prostaglandin $\mathrm{E}$ receptors," Carcinogenesis, vol. 32, no. 1, pp. 86-92, 2011.

[31] Y. Kobayashi, Y. Nakano, M. Kizaki, K. Hoshikuma, Y. Yokoo, and T. Kamiya, "Capsaicin-like anti-obese activities of evodiamine from fruits of Evodia rutaecarpa, a vanilloid receptor agonist," Planta Medica, vol. 67, no. 7, pp. 628-633, 2001.

[32] Y. Kobayashi, "The nociceptive and anti-nociceptive effects of evodiamine from fruits of Evodia rutaecarpa in mice," Planta Medica, vol. 69, no. 5, pp. 425-428, 2003.

[33] Y. W. Shin, E. A. Bae, X. F. Cai, J. J. Lee, and D. H. Kim, "In vitro and in vivo antiallergic effect of the fructus of Evodia rutaecarpa and its constituents," Biological and Pharmaceutical Bulletin, vol. 30, no. 1, pp. 197-199, 2007.

[34] H. C. Ko, Y. H. Wang, K. T. Liou et al., "Anti-inflammatory effects and mechanisms of the ethanol extract of Evodia rutaecarpa and its bioactive components on neutrophils and microglial cells," European Journal of Pharmacology, vol. 555, no. 2-3, pp. 211-217, 2007.

[35] M. Ogasawara, T. Matsubara, and H. Suzuki, "Inhibitory effects of evodiamine on in vitro invasion and experimental lung metastasis of murine colon cancer cells," Biological and Pharmaceutical Bulletin, vol. 24, no. 8, pp. 917-920, 2001.

[36] M. Ogasawara, T. Matsunaga, S. Takahashi, I. Saiki, and H. Suzuki, "Anti-invasive and metastatic activities of evodiamine," Biological and Pharmaceutical Bulletin, vol. 25, no. 11, pp. 1491-1493, 2002.

[37] X. F. Fei, B. X. Wang, T. J. Li et al., "Evodiamine, a constituent of Evodiae Fructus, induces anti-proliferating effects in tumor cells," Cancer Science, vol. 94, no. 1, pp. 9298, 2003.

[38] Y. Zhang, L. J. Wu, S. I. Tashiro, S. Onodera, and T. Ikejima, "Intracellular regulation of evodiamine-induced A375-S2 cell death," Biological and Pharmaceutical Bulletin, vol. 26, no. 11, pp. 1543-1547, 2003.

[39] K. G. Shyu, S. Lin, C. C. Lee et al., "Evodiamine inhibits in vitro angiogenesis: implication for antitumorgenicity," Life Sciences, vol. 78, no. 19, pp. 2234-2243, 2006.

[40] T. J. Lee, E. J. Kim, S. Kim et al., "Caspase-dependent and caspase-independent apoptosis induced by evodiamine in human leukemic U937 cells," Molecular Cancer Therapeutics, vol. 5, no. 9, pp. 2398-2407, 2006.

[41] C. Wang, S. Li, and M. W. Wang, "Evodiamine-induced human melanoma A375-S2 cell death was mediated by $\mathrm{PI} 3 \mathrm{~K} / \mathrm{Akt} / \mathrm{caspase}$ and Fas-L/NF- $\kappa \mathrm{B}$ signaling pathways and augmented by ubiquitin-proteasome inhibition," Toxicology in Vitro, vol. 24, no. 3, pp. 898-904, 2010.

[42] J. Yang, L. J. Wu, S. I. Tashino, S. Onodera, and T. Ikejima, "Reactive oxygen species and nitric oxide regulate mitochondriadependent apoptosis and autophagy in evodiaminetreated human cervix carcinoma HeLa cells," Free Radical Research, vol. 42, no. 5, pp. 492-504, 2008.

[43] Y. Zhang, Q. H. Zhang, L. J. Wu, S. I. Tashiro, S. Onodera, and T. Ikejima, "Atypical apoptosis in L929 cells induced by evodiamine isolated from Evodia rutaecarpa," Journal of Asian Natural Products Research, vol. 6, no. 1, pp. 19-27, 2004.
[44] C. H. Liao, S. L. Pan, J. H. Guh et al., "Antitumor mechanism of evodiamine, a constituent from Chinese herb Evodiae fructus, in human multiple-drug resistant breast cancer NCI/ADR-RES cells in vitro and in vivo," Carcinogenesis, vol. 26, no. 5, pp. 968-975, 2005.

[45] H. P. Tsai, L. W. Lin, Z. Y. Lai et al., "Immobilizing topoisomerase I on a surface plasmon resonance biosensor chip to screen for inhibitors," Journal of Biomedical Science, vol. 17, no. 1, article 49, 2010.

[46] A. L. F. Chan, W. S. Chang, L. M. Chen et al., "Evodiamine stabilizes topoisomerase I-DNA cleavable complex to inhibit topoisomerase I activity," Molecules, vol. 14, no. 4, pp. 1342$1352,2009$.

[47] G. Dong, C. Sheng, S. Wang, Z. Miao, J. Yao, and W. Zhang, "Selection of evodiamine as a novel topoisomerase i inhibitor by structure-based virtual screening and hit optimization of evodiamine derivatives as antitumor agents," Journal of Medicinal Chemistry, vol. 53, no. 21, pp. 7521-7531, 2010.

[48] S. F. Kan, W. J. Huang, L. C. Lin, and P. S. Wang, "Inhibitory effects of evodiamine on the growth of human prostate cancer cell line LNCaP," International Journal of Cancer, vol. 110, no. 5, pp. 641-651, 2004.

[49] Y. C. Huang, J. H. Guh, and C. M. Teng, "Induction of mitotic arrest and apoptosis by evodiamine in human leukemic Tlymphocytes," Life Sciences, vol. 75, no. 1, pp. 35-49, 2004.

[50] J. Yang, L. J. Wu, S. I. Tashino, S. Onodera, and T. Ikejima, "Critical roles of reactive oxygen species in mitochondrial permeability transition in mediating evodiamine-induced human melanoma A375-S2 cell apoptosis," Free Radical Research, vol. 41, no. 10, pp. 1099-1108, 2007.

[51] J. P. Lai, X. W. He, Y. Jiang, and F. Chen, "Preparative separation and determination of matrine from the Chinese medicinal plant Sophora flavescens Ait by molecularly imprinted solid-phase extraction," Analytical and Bioanalytical Chemistry, vol. 375, no. 2, pp. 264-269, 2003.

[52] X. Li, R. Zhou, P. Zheng et al., "Cardioprotective effect of matrine on isoproterenol-induced cardiotoxicity in rats," Journal of Pharmacy and Pharmacology, vol. 62, no. 4, pp. 514-520, 2010.

[53] Y. Xing, F. Yan, Y. Liu, Y. Liu, and Y. Zhao, "Matrine inhibits 3T3-L1 preadipocyte differentiation associated with suppression of ERK1/2 phosphorylation," Biochemical and Biophysical Research Communications, vol. 396, no. 3, pp. 691-695, 2010.

[54] J. Zheng, P. Zheng, X. Zhou et al., "Relaxant effects of matrine on aortic smooth muscles of guinea pigs," Biomedical and Environmental Sciences, vol. 22, no. 4, pp. 327-332, 2009.

[55] Y. Long, X. T. Lin, K. L. Zeng, and L. Zhang, "Efficacy of intramuscular matrine in the treatment of chronic hepatitis B," Hepatobiliary and Pancreatic Diseases International, vol. 3, no. 1, pp. 69-72, 2004.

[56] B. Zhang, Z. Y. Liu, Y. Y. Li et al., "Antiinflammatory effects of matrine in LPS-induced acute lung injury in mice," European Journal of Pharmaceutical Sciences, vol. 44, no. 5, pp. 573-579, 2011.

[57] Y. Han, S. Zhang, J. Wu et al., "Matrine induces apoptosis of human multiple myeloma cells via activation of the mitochondrial pathway," Leukemia and Lymphoma, vol. 51, no. 7, pp. 1337-1346, 2010.

[58] L. Zhang, T. Wang, X. Wen et al., "Effect of matrine on HeLa cell adhesion and migration," European Journal of Pharmacology, vol. 563, no. 1-3, pp. 69-76, 2007. 
[59] Z. J. Dai, J. Gao, Z. Z. Ji et al., "Matrine induces apoptosis in gastric carcinoma cells via alteration of Fas/FasL and activation of caspase-3," Journal of Ethnopharmacology, vol. 123, no. 1, pp. 91-96, 2009.

[60] T. Liu, Y. Song, H. Chen, S. Pan, and X. Sun, "Matrine inhibits proliferation and induces apoptosis of pancreatic cancer cells in vitro and in vivo," Biological and Pharmaceutical Bulletin, vol. 33, no. 10, pp. 1740-1745, 2010.

[61] C. Z. Liang, J. K. Zhang, Z. Shi, B. Liu, C. Q. Shen, and H. M. Tao, "Matrine induces caspase-dependent apoptosis in human osteosarcoma cells in vitro and in vivo through the upregulation of Bax and Fas/FasL and downregulation of Bcl2," Cancer Chemotherapy and Pharmacology, vol. 69, no. 2, pp. 317-331, 2011.

[62] P. Zhang, Z. Wang, T. Chong et al., "Matrine inhibits proliferation and induces apoptosis of the androgenindependent prostate cancer cell line PC-3," Molecular Medicine Reports, vol. 5, no. 3, pp. 783-787, 2012.

[63] Z. Zhang, X. Wang, W. Wu et al., "Effects of matrine on proliferation and apoptosis in gallbladder carcinoma cells (GBC-SD)," Phytotherapy research, vol. 26, no. 6, pp. 932937, 2011.

[64] H. Jiang, C. Hou, S. Zhang et al., "Matrine upregulates the cell cycle protein E2F-1 and triggers apoptosis via the mitochondrial pathway in K562 cells," European Journal of Pharmacology, vol. 559, no. 2-3, pp. 98-108, 2007.

[65] J. Q. Zhang, Y. M. Li, T. Liu et al., "Antitumor effect of matrine in human hepatoma G2 cells by inducing apoptosis and autophagy," World Journal of Gastroenterology, vol. 16, no. 34, pp. 4281-4290, 2010.

[66] J. Zhang, Y. Li, X. Chen et al., "Autophagy is involved in anticancer effects of matrine on SGC-7901 human gastric cancer cells," Oncology Reports, vol. 26, no. 1, pp. 115-124, 2011.

[67] L. P. Zhang, J. K. Jiang, J. W. O. Tam et al., "Effects of Matrine on proliferation and differentiation in K-562 cells," Leukemia Research, vol. 25, no. 9, pp. 793-800, 2001.

[68] H. Li, G. Tan, X. Jiang et al., "Therapeutic effects of matrine on primary and metastatic breast cancer," American Journal of Chinese Medicine, vol. 38, no. 6, pp. 1115-1130, 2010.

[69] L. Ma, S. Wen, Y. Zhan, Y. He, X. Liu, and J. Jiang, "Anticancer effects of the Chinese medicine matrine on murine hepatocellular carcinoma cells," Planta Medica, vol. 74, no. 3, pp. 245-251, 2008.

[70] W. Zhang, B. T. Dai, and Y. H. Xu, "Effects of matrine on invasion and metastasis of leukemia cell line Jurkat," Zhongguo Zhong xi yi jie he za zhi, vol. 28, no. 10, pp. 907911, 2008.

[71] P. Yu, Q. Liu, K. Liu, K. Yagasaki, E. Wu, and G. Zhang, "Matrine suppresses breast cancer cell proliferation and invasion via VEGF-Akt-NF- $\kappa \mathrm{B}$ signaling," Cytotechnology, vol. 59, no. 3, pp. 219-229, 2009.

[72] H. B. Yu, H. F. Zhang, D. Y. Li, X. Zhang, H. Z. Xue, and S. H. Zhao, "Matrine inhibits matrix metalloproteinase-9 expression and invasion of human hepatocellular carcinoma cells," Journal of Asian Natural Products Research, vol. 13, no. 3, pp. 242-250, 2011.

[73] C. Luo, H. J. Zhong, L. M. Zhu et al., "Inhibition of matrine against gastric cancer cell line MNK45 growth and its antitumor mechanism," Molecular Biology Reports, vol. 39, no. 5, pp. 5459-5464, 2011.

[74] A. Szallasi, "Piperine: researchers discover new flavor in an ancient spice," Trends in Pharmacological Sciences, vol. 26, no. 9, pp. 437-439, 2005.
[75] K. Srinivasan, "Black pepper and its pungent principlepiperine: a review of diverse physiological effects," Critical Reviews in Food Science and Nutrition, vol. 47, no. 8, pp. 735748, 2007.

[76] G. S. Bae, M. S. Kim, W. S. Jung et al., "Inhibition of lipopolysaccharide-induced inflammatory responses by piperine," European Journal of Pharmacology, vol. 642, no. 13, pp. 154-162, 2010.

[77] S. A. Lee, S. S. Hong, X. H. Han et al., "Piperine from the fruits of Piper longum with inhibitory effect on monoamine oxidase and antidepressant-like activity," Chemical and Pharmaceutical Bulletin, vol. 53, no. 7, pp. 832-835, 2005.

[78] S. Li, C. Wang, M. Wang, W. Li, K. Matsumoto, and Y. Tang, "Antidepressant like effects of piperine in chronic mild stress treated mice and its possible mechanisms," Life Sciences, vol. 80, no. 15, pp. 1373-1381, 2007.

[79] N. Krishnakumar, S. Manoharan, P. R. Palaniappan, P. Venkatachalam, and M. G. A. Manohar, "Chemopreventive efficacy of piperine in 7,12-dimethyl benz [a] anthracene (DMBA)-induced hamster buccal pouch carcinogenesis: an FT-IR study," Food and Chemical Toxicology, vol. 47, no. 11, pp. 2813-2820, 2009.

[80] K. Selvendiran, S. M. Banu, and D. Sakthisekaran, "Oral supplementation of piperine leads to altered phase II enzymes and reduced DNA damage and DNA-protein cross links in Benzo(a)pyrene induced experimental lung carcinogenesis," Molecular and Cellular Biochemistry, vol. 268, no. 1-2, pp. 141-147, 2005.

[81] K. Selvendiran and D. Sakthisekaran, "Chemopreventive effect of piperine on modulating lipid peroxidation and membrane bound enzymes in benzo(a)pyrene induced lung carcinogenesis," Biomedicine and Pharmacotherapy, vol. 58, no. 4, pp. 264-267, 2004.

[82] K. Selvendiran, C. Thirunavukkarasu, J. P. V. Singh, R. Padmavathi, and D. Sakthisekaran, "Chemopreventive effect of piperine on mitochondrial TCA cycle and phase-I and glutathione-metabolizing enzymes in benzo(a)pyrene induced lung carcinogenesis in Swiss albino mice," Molecular and Cellular Biochemistry, vol. 271, no. 1-2, pp. 101-106, 2005.

[83] K. Selvendiran, J. P. V. Singh, K. B. Krishnan, and D. Sakthisekaran, "Cytoprotective effect of piperine against benzo[a]pyrene induced lung cancer with reference to lipid peroxidation and antioxidant system in Swiss albino mice," Fitoterapia, vol. 74, no. 1-2, pp. 109-115, 2003.

[84] A. Khajuria, N. Thusu, U. Zutshi, and K. L. Bedi, "Piperine modulation of carcinogen induced oxidative stress in intestinal mucosa," Molecular and Cellular Biochemistry, vol. 189, no. 1-2, pp. 113-118, 1998.

[85] S. Manoharan, S. Balakrishnan, V. P. Menon, L. M. Alias, and A. R. Reena, "Chemopreventive \& efficacy of curcumin and piperine during 7,12-dimethylbenz [a] anthracene-induced hamster buccal pouch carcinogenesis," Singapore Medical Journal, vol. 50, no. 2, pp. 139-146, 2009.

[86] D. P. Bezerra, F. O. Castro, A. P. N. N. Alves et al., "In vivo growth-inhibition of Sarcoma 180 by piplartine and piperine, two alkaloid amides from piper," Brazilian Journal of Medical and Biological Research, vol. 39, no. 6, pp. 801-807, 2006.

[87] M. Kakarala, D. E. Brenner, H. Korkaya et al., "Targeting breast stem cells with the cancer preventive compounds curcumin and piperine," Breast Cancer Research and Treatment, vol. 122, no. 3, pp. 777-785, 2010. 
[88] L. H. Lai, Q. H. Fu, Y. Liu et al., "Piperine suppresses tumor growth and metastasis in vitro and in vivo in a $4 \mathrm{~T} 1$ murine breast cancer model," Acta Pharmacologica Sinica, vol. 33, no. 4, pp. 523-530, 2012.

[89] Q. F. Song, Y. C. Qu, H. B. Zheng, G. H. Zhang, H. G. Lin, and J. L. Yang, "Differentiation of erythroleukemia K562 cells induced by piperine," Ai Zheng, vol. 27, no. 6, pp. 571-574, 2008.

[90] C. R. Pradeep and G. Kuttan, "Effect of piperine on the inhibition of lung metastasis induced B16F-10 melanoma cells in mice," Clinical and Experimental Metastasis, vol. 19, no. 8, pp. 703-708, 2002.

[91] Y. P. Hwang, H. J. Yun, H. G. Kim et al., "Suppression of phorbol-12-myristate-13-acetate-induced tumor cell invasion by piperine via the inhibition of PKC $\alpha /$ ERK1/2dependent matrix metalloproteinase-9 expression," Toxicology Letters, vol. 203, no. 1, pp. 9-19, 2011.

[92] C. R. Pradeep and G. Kuttan, "Piperine is a potent inhibitor of nuclear factor $-\kappa \mathrm{B}(\mathrm{NF}-\kappa \mathrm{B}), \mathrm{c}-\mathrm{Fos}, \mathrm{CREB}, \mathrm{ATF}-$ 2 and proinflammatory cytokine gene expression in $\mathrm{B} 16 \mathrm{~F}-10$ melanoma cells," International Immunopharmacology, vol. 4, no. 14, pp. 1795-1803, 2004.

[93] R. K. Bhardwaj, H. Glaeser, L. Becquemont, U. Klotz, S. K. Gupta, and M. F. Fromm, "Piperine, a major constituent of black pepper, inhibits human P-glycoprotein and CYP3A4," Journal of Pharmacology and Experimental Therapeutics, vol. 302, no. 2, pp. 645-650, 2002.

[94] S. Li, Y. Lei, Y. Jia, N. Li, M. Wink, and Y. Ma, "Piperine, a piperidine alkaloid from Piper nigrum re-sensitizes $\mathrm{P}$ gp, MRP1 and BCRP dependent multidrug resistant cancer cells," Phytomedicine, vol. 19, no. 1, pp. 83-87, 2011.

[95] P. Makhov, K. Golovine, D. Canter et al., "Co-administration of piperine and docetaxel results in improved anti-tumor efficacy via inhibition of CYP3A4 activity," Prostate, vol. 72, no. 6, pp. 661-667, 2011.

[96] G. B. Mahady and C. W. W. Beecher, "Quercetin-induced benzophenanthridine alkaloid production in suspension cell cultures of Sanguinaria canadensis," Planta Medica, vol. 60, no. 6, pp. 553-557, 1994.

[97] C. Vavrečková, I. Gawlik, and K. Müller, "Benzophenanthridine alkaloids of Chelidonium majus; I. Inhibition of 5- and 12-lipoxygenase by a non-redox mechanism," Planta Medica, vol. 62, no. 5, pp. 397-401, 1996.

[98] J. Lenfeld, M. Kroutil, and E. Marsalek, "Antiinflammatory activity of quaternary benzophenanthridine alkaloids from Chelidonium majus," Planta Medica, vol. 43, no. 2, pp. 161$165,1981$.

[99] T. K. Beuria, M. K. Santra, and D. Panda, "Sanguinarine blocks cytokinesis in bacteria by inhibiting FtsZ assembly a bundling," Biochemistry, vol. 44, no. 50, pp. 16584-16593, 2005.

[100] J. H. Jeng, H. L. Wu, B. R. Lin et al., "Antiplatelet effect of sanguinarine is correlated to calcium mobilization, thromboxane and cAMP production," Atherosclerosis, vol. 191, no. 2, pp. 250-258, 2007.

[101] H. Ahsan, S. Reagan-Shaw, J. Breur, and N. Ahmad, "Sanguinarine induces apoptosis of human pancreatic carcinoma AsPC-1 and BxPC-3 cells via modulations in Bcl-2 family proteins," Cancer Letters, vol. 249, no. 2, pp. 198-208, 2007.

[102] M. C. Chang, C. P. Chan, Y. J. Wang et al., "Induction of necrosis and apoptosis to $\mathrm{KB}$ cancer cells by sanguinarine is associated with reactive oxygen species production and mitochondrial membrane depolarization," Toxicology and Applied Pharmacology, vol. 218, no. 2, pp. 143-151, 2007.
[103] E. Debiton, J. C. Madelmont, J. Legault, and C. Barthomeuf, "Sanguinarine-induced apoptosis is associated with an early and severe cellular glutathione depletion," Cancer Chemotherapy and Pharmacology, vol. 51, no. 6, pp. 474-482, 2003.

[104] A. R. Hussain, N. A. Al-Jomah, A. K. Siraj et al., "Sanguinarine-dependent induction of apoptosis in primary effusion lymphoma cells," Cancer Research, vol. 67, no. 8, pp. 3888-3897, 2007.

[105] S. Kim, T. J. Lee, J. Leem, S. C. Kyeong, J. W. Park, and K. K. Taeg, "Sanguinarine-induced apoptosis: generation of ROS, down-regulation of Bcl-2, c-FLIP, and synergy with TRAIL," Journal of Cellular Biochemistry, vol. 104, no. 3, pp. 895-907, 2008.

[106] V. M. Adhami, M. H. Aziz, H. Mukhtar, and N. Ahmad, "Activation of prodeath Bcl-2 family proteins and mitochondrial apoptosis pathway by sanguinarine in immortalized human HaCaT keratinocytes," Clinical Cancer Research, vol. 9, no. 8, pp. 3176-3182, 2003.

[107] V. M. Adhami, M. H. Aziz, S. R. Reagan-Shaw, M. Nihal, H. Mukhtar, and N. Ahmad, "Sanguinarine causes cell cyle blockade and apoptosis of human prostate carcinoma cells via modulation of cylin kinase inhibitor-cyclin-cyclindependent kinase machinery," Molecular Cancer Therapeutics, vol. 3, no. 8, pp. 933-940, 2004.

[108] P. Weerasinghe, S. Hallock, S. C. Tang, B. Trump, and A. Liepins, "Sanguinarine overcomes P-glycoprotein-mediated multidrug-resistance via induction of apoptosis and oncosis in CEM-VLB 1000 cells," Experimental and Toxicologic Pathology, vol. 58, no. 1, pp. 21-30, 2006.

[109] I. De Stefano, G. Raspaglio, G. F. Zannoni et al., "Antiproliferative and antiangiogenic effects of the benzophenanthridine alkaloid sanguinarine in melanoma," Biochemical Pharmacology, vol. 78, no. 11, pp. 1374-1381, 2009.

[110] Y. H. Choi, W. Y. Choi, S. H. Hong et al., "Anti-invasive activity of sanguinarine through modulation of tight junctions and matrix metalloproteinase activities in MDAMB-231 human breast carcinoma cells," Chemico-Biological Interactions, vol. 179, no. 2-3, pp. 185-191, 2009.

[111] J. Huh, A. Liepins, J. Zielonka, C. Andrekopoulos, B. Kalyanaraman, and A. Sorokin, "Cyclooxygenase 2 rescues LNCaP prostate cancer cells from sanguinarine-induced apoptosis by a mechanism involving inhibition of nitric oxide synthase activity," Cancer Research, vol. 66, no. 7, pp. 3726-3736, 2006.

[112] H. Ahsan, S. Reagan-Shaw, D. M. Eggert et al., "Protective effect of sanguinarine on ultraviolet B-mediated damages in SKH-1 hairless mouse skin: implications for prevention of skin cancer," Photochemistry and Photobiology, vol. 83, no. 4, pp. 986-993, 2007.

[113] B. C. Jang, J. G. Park, D. K. Song et al., "Sanguinarine induces apoptosis in A549 human lung cancer cells primarily via cellular glutathione depletion," Toxicology in Vitro, vol. 23, no. 2, pp. 281-287, 2009.

[114] Y. J. Cai, J. J. Lu, H. Zhu et al., "Salvicine triggers DNA double-strand breaks and apoptosis by GSH-depletiondriven $\mathrm{H}_{2} \mathrm{O}_{2}$ generation and topoisomerase II inhibition," Free Radical Biology and Medicine, vol. 45, no. 5, pp. 627-635, 2008.

[115] Y. Cai, J. Lu, Z. Miao, L. Lin, and J. Ding, "Reactive oxygen species contribute to cell killing and P-glycoprotein downregulation by salvicine in multidrug resistant K562/A02 cells," Cancer Biology and Therapy, vol. 6, no. 11, pp. 17941799, 2007. 
[116] A. Vogt, A. Tamewitz, J. Skoko, R. P. Sikorski, K. A. Giuliano, and J. S. Lazo, "The benzo[c]phenanthridine alkaloid, sanguinarine, is a selective, cell-active inhibitor of mitogenactivated protein kinase phosphatase-1," Journal of Biological Chemistry, vol. 280, no. 19, pp. 19078-19086, 2005.

[117] M. Lopus and D. Panda, "The benzophenanthridine alkaloid sanguinarine perturbs microtubule assembly dynamics through tubulin binding: a possible mechanism for its antiproliferative activity," FEBS Journal, vol. 273, no. 10, pp. 2139-2150, 2006.

[118] J. Holy, G. Lamont, and E. Perkins, "Disruption of nucleocytoplasmic trafficking of cylin DI and topoisomerase II by sanguinarine," BMC Cell Biology, vol. 7, article 13, 2006.

[119] M. M. Chaturvedi, A. Kumar, B. G. Darnay, G. B. N. Chainy, S. Agarwal, and B. B. Aggarwal, "Sanguinarine (pseudochelerythrine) is a potent inhibitor of NF- $\kappa \mathrm{B}$ activation, $\mathrm{I} \kappa \mathrm{B} \alpha$ phosphorylation, and degradation," Journal of Biological Chemistry, vol. 272, no. 48, pp. 30129-30134, 1997.

[120] M. Sun, C. Liu, N. Nadiminty et al., "Inhibition of Stat3 activation by sanguinarine suppresses prostate cancer cell growth and invasion," Prostate, vol. 72, no. 1, pp. 82-89, 2011.

[121] D. G. Li, Z. R. Wang, and H. M. Lu, "Pharmacology of tetrandrine and its therapeutic use in digestive diseases," World Journal of Gastroenterology, vol. 7, no. 5, pp. 627-629, 2001.

[122] L. T. Ng, L. C. Chiang, Y. T. Lin, and C. C. Lin, "Antiproliferative and apoptotic effects of tetrandrine on different human hepatoma cell lines," American Journal of Chinese Medicine, vol. 34, no. 1, pp. 125-135, 2006.

[123] P. L. Kuo and C. C. Lin, "Tetrandrine-induced cell cycle arrest and apoptosis in Hep G2 cells," Life Sciences, vol. 73, no. 2, pp. 243-252, 2003.

[124] L. H. Meng, H. Zhang, L. Hayward, H. Takemura, R. G. Shao, and Y. Pommier, "Tetrandrine induces early G1 arrest in human colon carcinoma cells by down-regulating the activity and inducing the degradation of G 1-S-specific cyclin-dependent kinases and by inducing p53 and p21Cip1," Cancer Research, vol. 64, no. 24, pp. 9086-9092, 2004.

[125] X. Li, B. Su, R. Liu, D. Wu, and D. He, “Tetrandrine induces apoptosis and triggers caspase cascade in human bladder cancer cells," Journal of Surgical Research, vol. 166, no. 1, pp. e45-e51, 2011.

[126] B. C. He, J. L. Gao, B. Q. Zhang et al., "Tetrandrine inhibits Wnt/beta-catenin signaling and suppresses tumor growth of human colorectal cancer," Molecular Pharmacology, vol. 79, no. 2, pp. 211-219, 2011.

[127] J. M. Wu, Y. Chen, J. C. Chen, T. Y. Lin, and S. H. Tseng, "Tetrandrine induces apoptosis and growth suppression of colon cancer cells in mice," Cancer Letters, vol. 287, no. 2, pp. 187-195, 2010.

[128] S. M. Yoo, S. H. Oh, S. J. Lee et al., "Inhibition of proliferation and induction of apoptosis by tetrandrine in HepG2 cells," Journal of Ethnopharmacology, vol. 81, no. 2, pp. 225-229, 2002.

[129] J. H. Lee, G. H. Kang, K. C. Kim et al., "Tetrandrineinduced cell cycle arrest and apoptosis in A549 human lung carcinoma cells," International Journal of Oncology, vol. 21, no. 6, pp. 1239-1244, 2002.

[130] Y. L. Lai, Y. J. Chen, T. Y. Wu et al., "Induction of apoptosis in human leukemic U937 cells by tetrandrine," Anti-Cancer Drugs, vol. 9, no. 1, pp. 77-81, 1998.
[131] Y. Chen, J. C. Chen, and S. H. Tseng, "Tetrandrine suppresses tumor growth and angiogenesis of gliomas in rats," International Journal of Cancer, vol. 124, no. 10, pp. 2260-2269, 2009.

[132] K. H. Chang, H. F. Liao, H. H. Chang et al., "Inhibitory effect of tetrandrine on pulmonary metastases in CT26 colorectal adenocarcinoma-bearing BALB/c mice," American Journal of Chinese Medicine, vol. 32, no. 6, pp. 863-872, 2004.

[133] L. W. Fu, Y. M. Zhang, Y. J. Liang, X. P. Yang, and Q. C. Pan, "The multidrug resistance of tumour cells was reversed by tetrandrine in vitro and in xenografts derived from human breast adenocarcinoma MCF-7/adr cells," European Journal of Cancer, vol. 38, no. 3, pp. 418-426, 2002.

[134] X. Zhu, M. Sui, and W. Fan, "In vitro and in vivo characterizations of tetrandrine on the reversal of P-glycoproteinmediated drug resistance to paclitaxel," Anticancer Research, vol. 25, no. 3, pp. 1953-1962, 2005.

[135] L. Fu, Y. Liang, L. Deng et al., "Characterization of tetrandrine, a potent inhibitor of P-glycoprotein-mediated multidrug resistance," Cancer Chemotherapy and Pharmacology, vol. 53, no. 4, pp. 349-356, 2004.

[136] Y. Zhang, C. Wang, H. Wang, K. Wang, Y. Du, and J. Zhang, "Combination of Tetrandrine with cisplatin enhances cytotoxicity through growth suppression and apoptosis in ovarian cancer in vitro and in vivo," Cancer Letters, vol. 304, no. 1, pp. 21-32, 2011.

[137] J. Wei, B. Liu, L. Wang, X. Qian, Y. Ding, and L. Yu, "Synergistic interaction between tetrandrine and chemotherapeutic agents and influence of tetrandrine on chemotherapeutic agent-associated genes in human gastric cancer cell lines," Cancer Chemotherapy and Pharmacology, vol. 60, no. 5, pp. 703-711, 2007.

[138] E. Iorns, C. J. Lord, and A. Ashworth, "Parallel RNAi and compound screens identify the PDK1 pathway as a target for tamoxifen sensitization," Biochemical Journal, vol. 417, no. 1, pp. 361-370, 2009.

[139] J. Yu, F. Liu, M. Sun et al., "Enhancement of radiosensitivity and the potential mechanism on human esophageal carcinoma cells by tetrandrine," Cancer Biotherapy and Radiopharmaceuticals, vol. 26, no. 4, pp. 437-442, 2011.

[140] K. H. Chang, M. L. Chen, H. C. Chen, Y. W. Huang, T. Y. Wu, and Y. J. Chen, "Enhancement of radiosensitivity in human glioblastoma U138MG cells by tetrandrine," Neoplasma, vol. 46, no. 3, pp. 196-200, 1999.

[141] Y. Chen, J. C. Chen, and S. H. Tseng, "Effects of tetrandrine plus radiation on neuroblastoma cells," Anticancer Research, vol. 29, no. 8, pp. 3163-3171, 2009.

[142] X. C. Sun, H. Y. Cheng, Y. X. Deng, R. G. Shao, and J. Ma, "Tetrandrine: a potent abrogator of G2 checkpoint function in tumor cells and its mechanism," Biomedical and Environmental Sciences, vol. 20, no. 6, pp. 495-501, 2007.

[143] X. Sun, R. Xu, Y. Deng et al., "Effects of tetrandrine on apoptosis and radiosensitivity of nasopharyngeal carcinoma cell line CNE," Acta Biochimica et Biophysica Sinica, vol. 39, no. 11, pp. 869-878, 2007.

[144] J. A. McCubrey, J. Bäsecke, M. Cervello, A. M. Martelli, and R. A. Franklin, "GSK- $3 \beta$ is a critical mediator of tetrandrine induced cell cycle arrest and cytotoxicity," Cancer Biology and Therapy, vol. 7, no. 7, p. 1079, 2008.

[145] X. L. Chen, K. H. Ren, H. W. He et al., "Involvement of PI3K/AKT/GSK3beta pathway in tetrandrine-induced G1 
arrest and apoptosis," Cancer Biology and Therapy, vol. 7, no. 7, pp. 1073-1078, 2008.

[146] C. Liu, K. Gong, X. Mao, and W. Li, “Tetrandrine induces apoptosis by activating reactive oxygen species and repressing Akt activity in human hepatocellular carcinoma," International Journal of Cancer, vol. 129, no. 6, pp. 1519-1531, 2011.

[147] S. H. Oh and B. H. Lee, "Induction of apoptosis in human hepatoblastoma cells by tetrandrine via caspase-dependent Bid cleavage and cytochrome c release," Biochemical Pharmacology, vol. 66, no. 5, pp. 725-731, 2003.

[148] H. S. Cho, S. H. Chang, Y. S. Chung et al., "Synergistic effect of ERK inhibition on tetrandrine-induced apoptosis in A549 human lung carcinoma cells," Journal of Veterinary Science, vol. 10, no. 1, pp. 23-28, 2009.

[149] A. K. Larsen, L. Grondard, J. Couprie et al., "The antileukemic alkaloid fagaronine is an inhibitor of DNA topoisomerases I and II," Biochemical Pharmacology, vol. 46, no. 8, pp. 1403-1412, 1993.

[150] D. Lamoral-Theys, C. Decaestecker, V. Mathieu et al., "Lycorine and its derivatives for anticancer drug design," Mini-Reviews in Medicinal Chemistry, vol. 10, no. 1, pp. 4150, 2010.

[151] J. Chen, J. Wang, L. Lin et al., "Inhibition of STAT3 signaling pathway by nitidine chloride suppressed the angiogenesis and growth of human gastric cancer," Molecular Cancer Therapeutics, vol. 11, no. 2, pp. 277-287, 2011.

[152] Y. B. Ji, S. Y. Gao, C. F. Ji, and X. Zou, "Induction of apoptosis in HepG2 cells by solanine and Bcl-2 protein," Journal of Ethnopharmacology, vol. 115, no. 2, pp. 194-202, 2008.

[153] X. M. Li, L. Z. Li, and S. L. Chen, "Inhibitory effects of sophocarpine on animal tumors," Acta Pharmacologica Sinica, vol. 5, no. 2, pp. 125-130, 1984.

[154] J. Jiang and C. Hu, "Evodiamine: a novel anti-cancer alkaloid from evodia rutaecarpa," Molecules, vol. 14, no. 5, pp. 18521859, 2009.

[155] Y. Q. Pei, "A review of pharmacology and clinical use of piperine and its derivatives," Epilepsia, vol. 24, no. 2, pp. 177$182,1983$.

[156] S. C. Lahiri and N. K. Dutta, "Berberine and chloramphenicol in the treatment of cholera and severe diarrhoea," Journal of the Indian Medical Association, vol. 48, no. 1, pp. 1-11, 1967.

[157] D. P. Bezerra, F. O. De Castro, A. P. N. N. Alves et al., "In vitro and in vivo antitumor effect of 5-FU combined with piplartine and piperine," Journal of Applied Toxicology, vol. 28, no. 2, pp. 156-163, 2008.

[158] M. J. Hu, H. Zeng, Y. L. Wu et al., "Synergistic effects of matrine and 5-fluorouracil on tumor growth of the implanted gastric cancer in nude mice," Chinese Journal of Digestive Diseases, vol. 6, no. 2, pp. 68-71, 2005.

[159] J. J. Lu, W. Pan, Y. J. Hu et al., "Multi-target drugs: the trend of drug research and development," PLoS ONE, vol. 7, no. 6, Article ID e40262, 2012.

[160] J. J. Lu, Y. J. Cai, and J. Ding, "Curcumin induces DNA damage and caffeine-insensitive cell cycle arrest in colorectal carcinoma HCT116 cells," Molecular and Cellular Biochemistry, vol. 354, no. 1-2, pp. 247-252, 2011.

[161] J. J. Lu, S. M. Chen, X. W. Zhang, J. Ding, and L. H. Meng, "The anti-cancer activity of dihydroartemisinin is associated with induction of iron-dependent endoplasmic reticulum stress in colorectal carcinoma HCT116 cells," Investigational New Drugs, vol. 29, no. 6, pp. 1276-1283, 2011.
[162] H. Zhu, X. W. Liu, W. J. Ding et al., "Up-regulation of death receptor 4 and 5 by celastrol enhances the anti-cancer activity of TRAIL/Apo-2L," Cancer Letters, vol. 297, no. 2, pp. 155$164,2010$.

[163] J. J. Lu, L. H. Meng, U. T. Shankavaram et al., "Dihydroartemisinin accelerates c-MYC oncoprotein degradation and induces apoptosis in c-MYC-overexpressing tumor cells," Biochemical Pharmacology, vol. 80, no. 1, pp. 22-30, 2010.

[164] S. Li, Z. Ji, M. Zou, X. Nie, Y. Shi, and G. Cheng, "Preparation, characterization, pharmacokinetics and tissue distribution of solid lipid nanoparticles loaded with tetrandrine," AAPS PharmSciTech, vol. 12, no. 3, pp. 1011-1018, 2011.

[165] Q. Tan, S. Liu, X. Chen et al., "Design and evaluation of a novel evodiamine-phospholipid complex for improved oral bioavailability," AAPS PharmSciTech, vol. 13, no. 2, pp. 534547, 2012.

[166] J. Tang, Y. Feng, S. Tsao, N. Wang, R. Curtain, and Y. Wang, "Berberine and Coptidis Rhizoma as novel antineoplastic agents: a review of traditional use and biomedical investigations," Journal of Ethnopharmacology, vol. 126, no. 1, pp. 5-17, 2009.

[167] E. Chan, "Displacement of bilirubin from albumin by berberine," Biology of the Neonate, vol. 63, no. 4, pp. 201-208, 1993.

[168] T. Y. K. Chan, "The prevalence use and harmful potential of some Chinese herbal medicines in babies and children," Veterinary and Human Toxicology, vol. 36, no. 3, pp. 238-240, 1994.

[169] R. K. S. Dogra, S. Khanna, and R. Shanker, "Immunotoxicological effects of piperine in mice," Toxicology, vol. 196, no. 3, pp. 229-236, 2004.

[170] M. B. Daware, A. M. Mujumdar, and S. Ghaskadbi, "Reproductive toxicity of piperine in Swiss albino mice," Planta Medica, vol. 66, no. 3, pp. 231-236, 2000.

[171] S. Unchern, H. Saito, and N. Nishiyama, "Selective cytotoxicity of piperine on cultured rat hippocampal neurons in comparison with cultured astrocytes: the possible involvement of lipid peroxidation," Biological and Pharmaceutical Bulletin, vol. 20, no. 9, pp. 958-961, 1997.

[172] C. S. Choy, K. P. Cheah, H. Y. Chiou et al., "Induction of hepatotoxicity by sanguinarine is associated with oxidation of protein thiols and disturbance of mitochondrial respiration," Journal of Applied Toxicology, vol. 28, no. 8, pp. 945956, 2008.

[173] W. H. Chan, "Embryonic toxicity of sanguinarine through apoptotic processes in mouse blastocysts," Toxicology Letters, vol. 205, no. 3, pp. 285-292, 2011. 


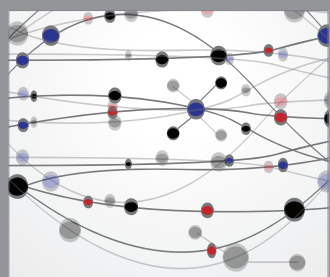

The Scientific World Journal
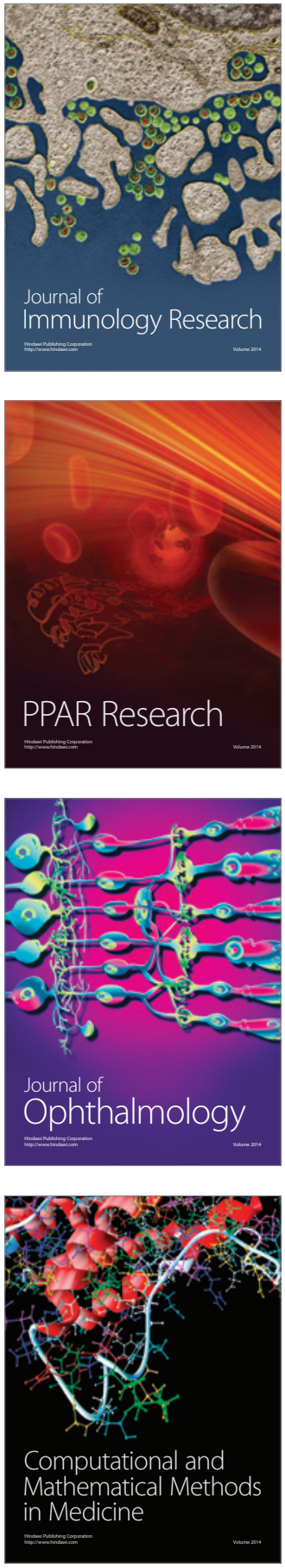

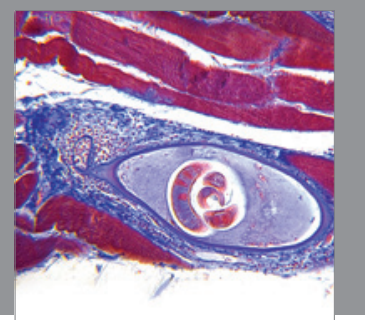

Gastroenterology

Research and Practice
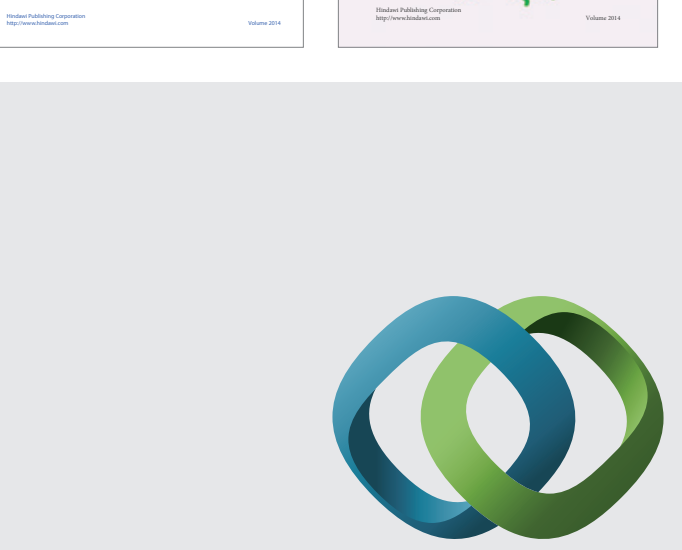

\section{Hindawi}

Submit your manuscripts at

http://www.hindawi.com
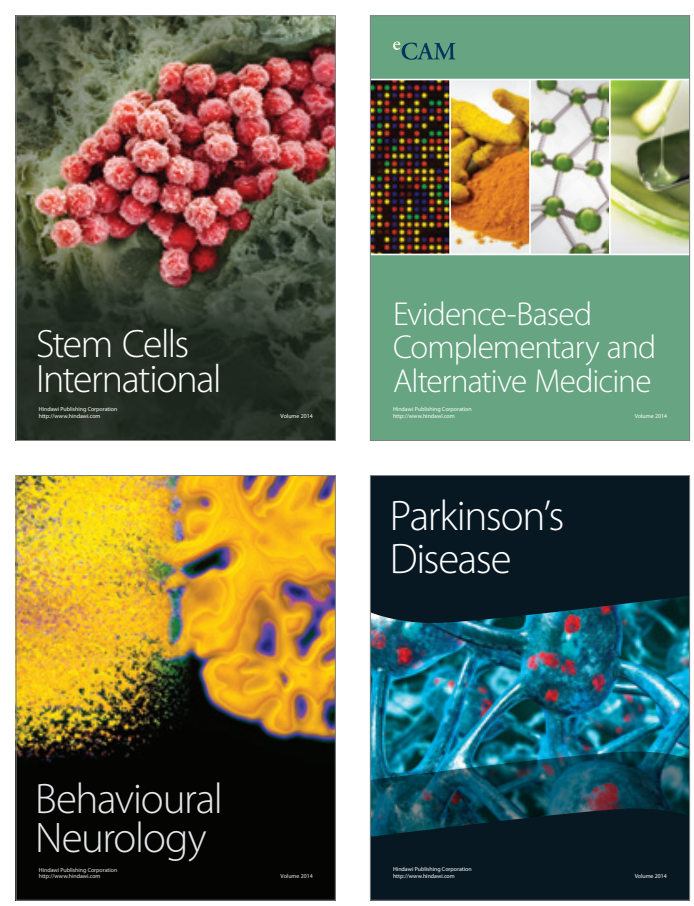

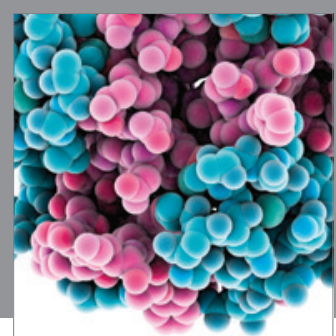

Journal of
Diabetes Research

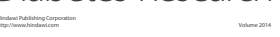

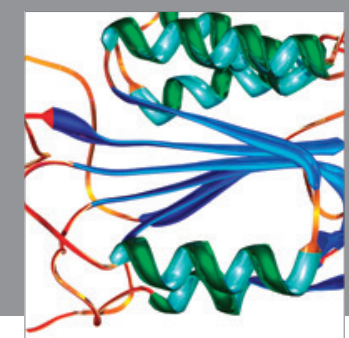

Disease Markers
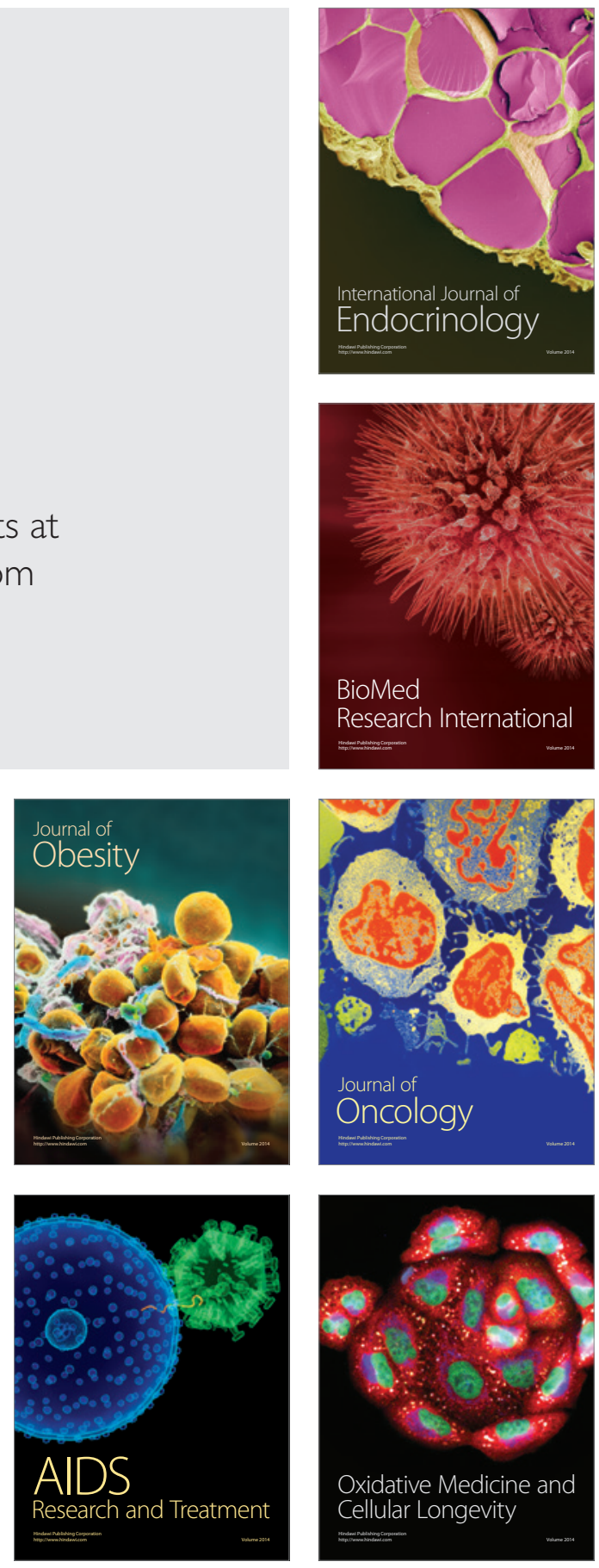